\title{
Unusual Cause of Recurrent Cholangitis: Gossypiboma
}

\author{
Bipadabhanjan Mallick ${ }^{1}$, Preetam Nath ${ }^{1}$, Dibya L. Praharaj ${ }^{1}$, Sarat C. Panigrahi ${ }^{1}$, Anil Anand ${ }^{1}$ \\ 1. Gastroenterology, Kalinga Institute of Medical Sciences, Bhubaneswar, IND
}

Corresponding author: Bipadabhanjan Mallick, drbipadabhanjan@gmail.com

\begin{abstract}
Gossypiboma refers to a retained surgical sponge that can occur after any type of surgery. Though it is a rare complication of surgery, the retention of surgical sponges still occurs. We report a case of a 70-year-old woman who presented with recurrent upper abdominal pain and fever. She had a prior history of cholecystectomy and choledochoduodenostomy. Magnetic resonance cholangiopancreatography showed a filling defect in common bile duct. However, during endoscopic retrograde cholangiopancreatography and common bile duct clearance, clumps of woven fibres were removed suggestive of gossypiboma.
\end{abstract}

Categories: Gastroenterology

Keywords: recurrent cholangitis, gossypiboma, endoscopic retrograde cholangiopancreatography

\section{Introduction}

A gossypiboma refers to a surgical sponge left inadvertently in the human body following a surgical procedure [1]. It is a rare event, with reported incidences of 1 in 1,000 to 1,500 in intra-abdominal open surgery [2]. The clinical presentation is variable depending on the site of retention and type of tissue reaction, which makes the clinical diagnosis often difficult [3]. Radiograph and computed tomography can readily detect gossypiboma because of the radiopaque filaments in the surgical sponges [4]. However, this can be overlooked owing to lack of clinical suspicions and familiarity with the imaging features. We report a case of gossypiboma presenting with recurrent cholangitis.

Received 03/24/2020

Review began 03/26/2020 Review ended 04/14/2020 Published 04/22/2020

() Copyright 2020

Mallick et al. This is an open access

article distributed under the terms of the Creative Commons Attribution License CC-BY 4.0., which permits unrestricted use, distribution, and reproduction in any medium, provided the original author and source are credited.

\section{Case Presentation}

A 70-year-old woman presented with upper abdominal pain and fever of one-week duration. She had similar presentation two months back to an outside hospital which was managed with antibiotics. She underwent open cholecystectomy elsewhere 20 years prior for symptomatic gallstones and choledochoduodenostomy 10 years prior for common bile duct (CBD) stones. Routine blood investigations showed raised total leukocyte count $\left(16.5 \times 10^{9} / \mathrm{L}\right)$, total bilirubin of $1.2 \mathrm{mg} / \mathrm{dL}$, serum glutamic oxaloacetic transaminase of 23 IU/L, serum glutamic pyruvic transaminase of $37 \mathrm{IU} / \mathrm{L}$, alkaline phosphatase of $240 \mathrm{IU} / \mathrm{L}$ (normal <104 IU/L) and gamma-glutamyl transferase of $110 \mathrm{IU} / \mathrm{L}$ (normal <39 IU/L). Contrast-enhanced magnetic resonance imaging of the abdomen with magnetic resonance cholangiopancreatography showed the presence of pneumobilia with patent choledochoduodenostomy site and filling defect in lower CBD. She was posted for endoscopic retrograde cholangiopancreatography (ERCP) and clearance of CBD. Contrast cholangiogram showed a patent choledochoduodenostomy site with filling defect in lower CBD (Figure 1). 


\section{Cureus}

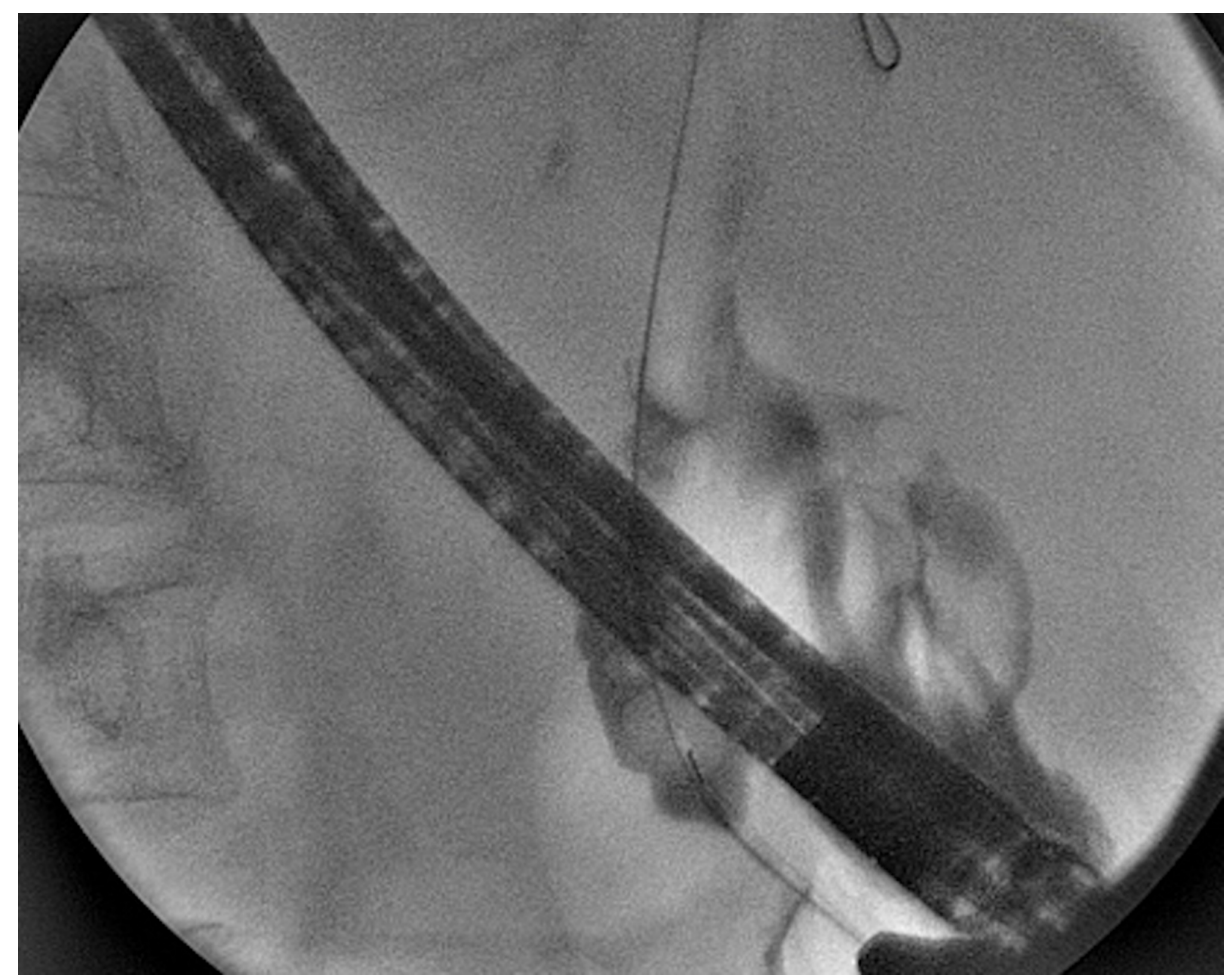

FIGURE 1: Contrast cholangiogram showing filling defect in lower common bile duct and patent choledochoduodenostomy site

Dormia basket was used to clear the CBD, but surprisingly clumps of woven fibres were removed (Figure 2).

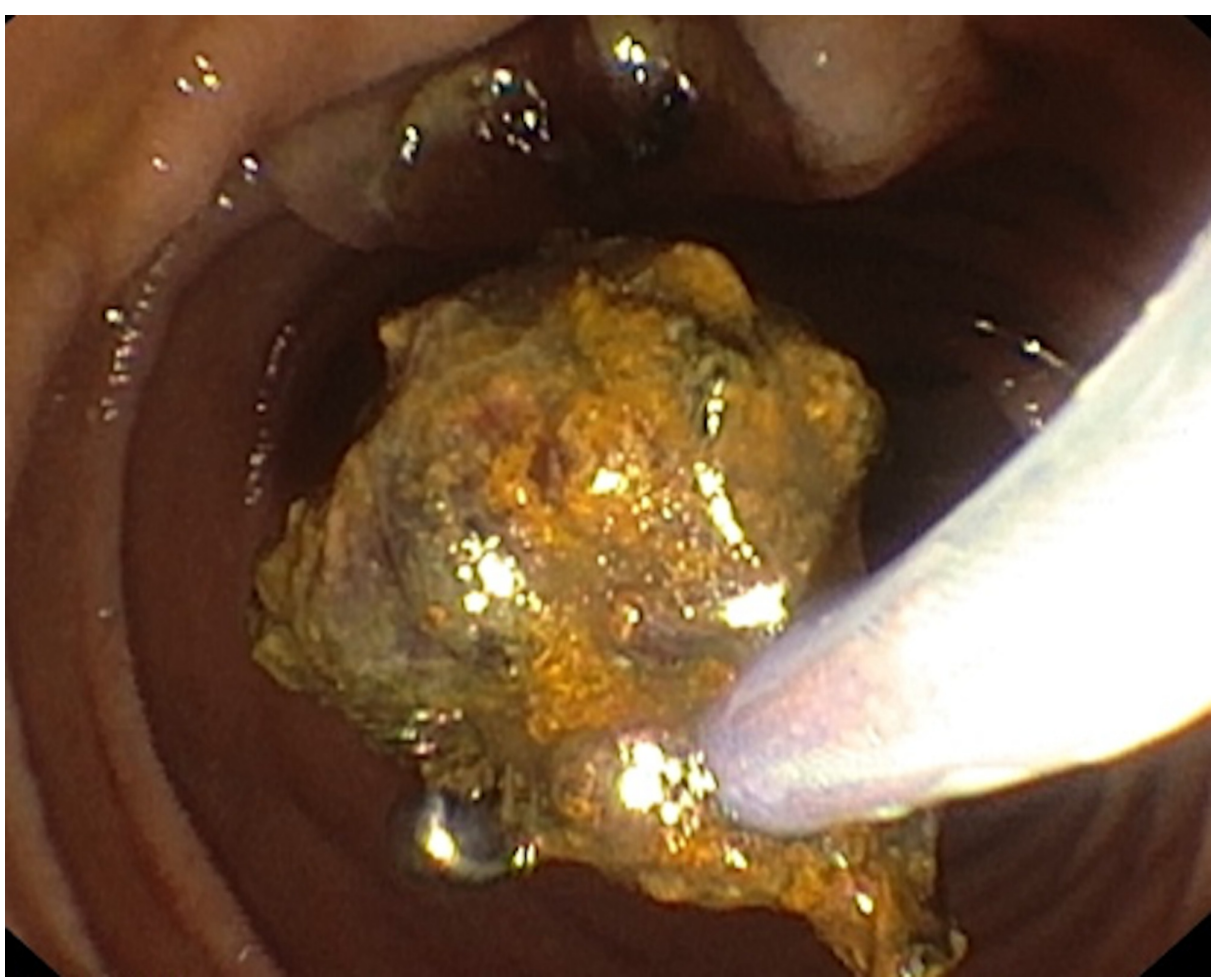

FIGURE 2: Clumps of woven fibres grasped with basket

The basket was changed to extraction balloon, and residual woven fibres were removed (Figure 3). 


\section{Cureus}

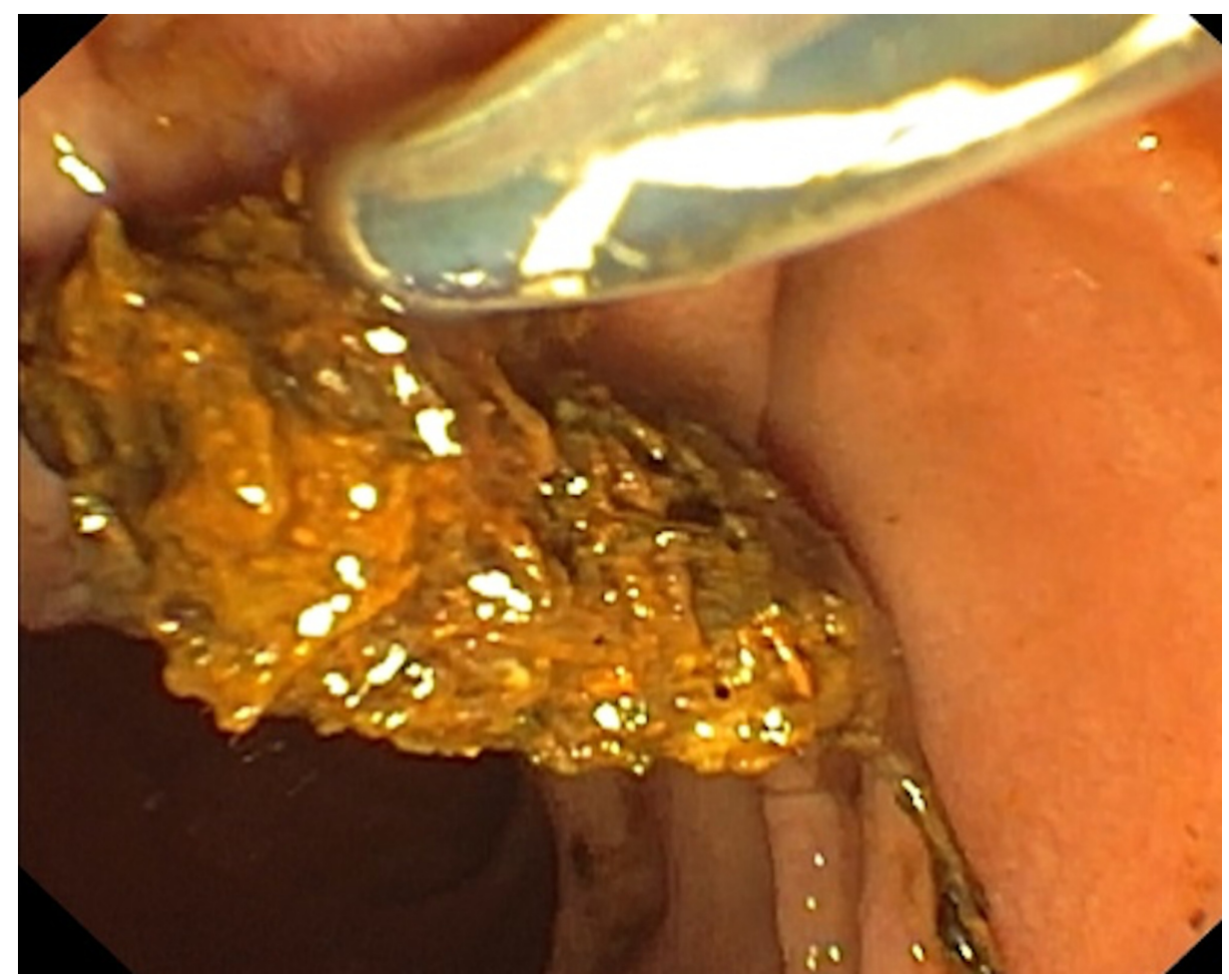

FIGURE 3: Clumps of woven fibres coming out with balloon sweep

Outside naked eye examination confirmed the retained surgical sponge (Figure 4).

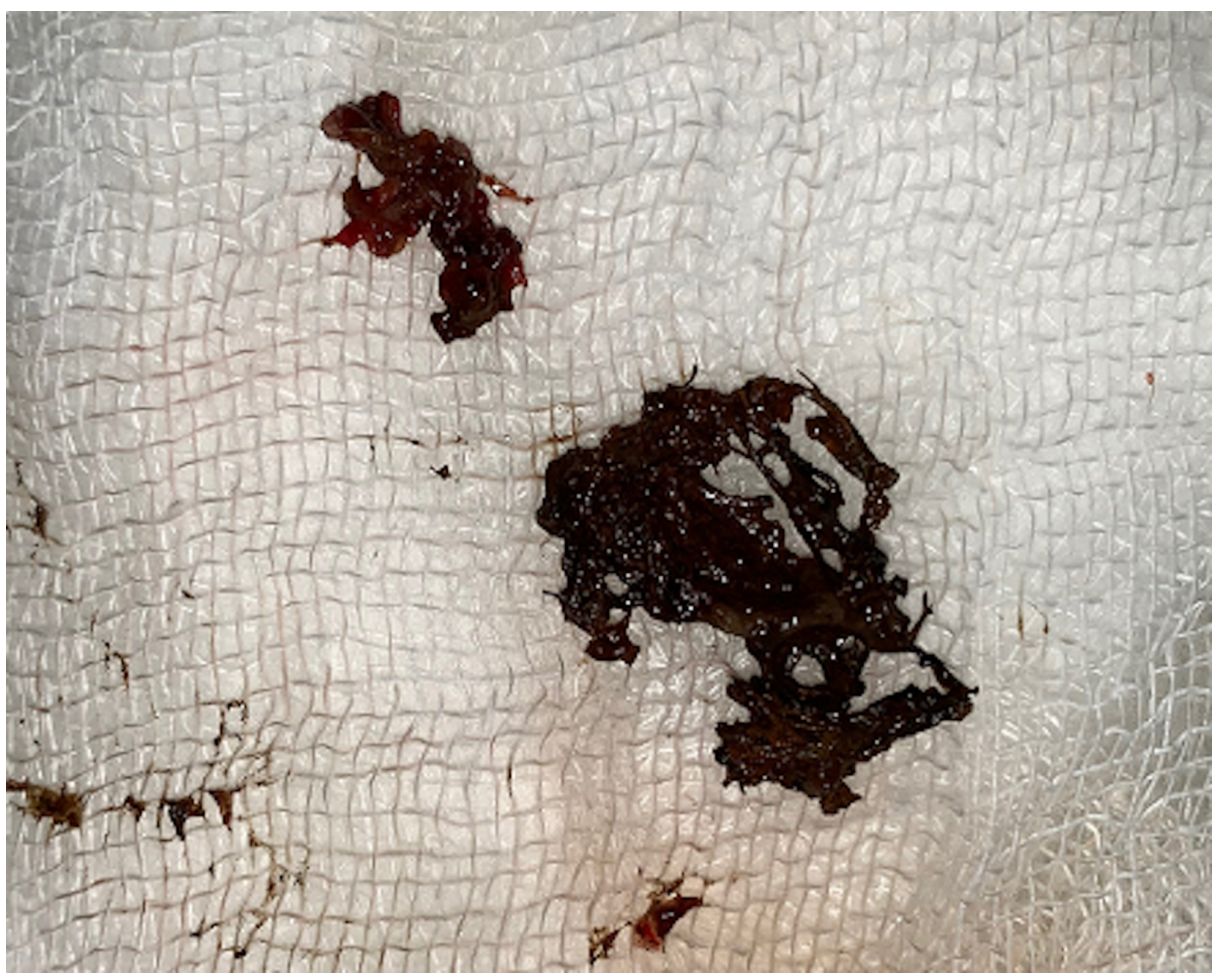

FIGURE 4: Part of the removed surgical sponge

At three-month follow-up, she is doing fine without any abdominal pain or fever.

\section{Discussion}


Gossypiboma refers to a surgical sponge left inadvertently in the human body following a surgical procedure and the subsequent tissue reaction around it [1]. Majority of gossypiboma are found in the abdomen and their clinical presentations are variable depending on the location and the type of tissue reaction [3]. The sponges are inert in human tissue and do not undergo decomposition. The retained surgical sponge causes a foreign body reaction in the form of an aseptic fibrinous response leading to formation of adhesions and encapsulation [5]. In case of high clinical suspicion, the diagnosis of gossypiboma is usually made by imaging studies [4]. The gossypiboma should be removed and surgery is the main stay of therapy [6]. Our case is unique in the sense that the gossypiboma was confined into CBD, causing recurrent cholangitis and it was removed completely by ERCP.

\section{Conclusions}

The diagnosis of a gossypiboma is not often easy and is often clinically unsuspected and may be first recognized on imaging. Awareness of the typical radiologic appearances is critical to the diagnosis gossypiboma.

\section{Additional Information \\ Disclosures}

Human subjects: Consent was obtained by all participants in this study. Conflicts of interest: In compliance with the ICMJE uniform disclosure form, all authors declare the following: Payment/services info: All authors have declared that no financial support was received from any organization for the submitted work. Financial relationships: All authors have declared that they have no financial relationships at present or within the previous three years with any organizations that might have an interest in the submitted work. Other relationships: All authors have declared that there are no other relationships or activities that could appear to have influenced the submitted work.

\section{References}

1. Karasaki T, Nomura Y, Nakagawa T, Tanaka N: Beware of gossypibomas. BMJ Case Rep. 2013, 2013:bcr2013010059. 10.1136/bcr-2013-010059

2. Cimsit B, Keskin M, Ozden I, Alper A: Obstructive jaundice due to a textiloma mimicking a common bile duct stone. J Hepatobiliary Pancreat Surg. 2006, 13:172-173. 10.1007/s00534-005-1022-z

3. Ojha S, Gall T, Sodergren MH, Jiao LR: A case of gossypiboma mimicking intrahepatic cholangiocarcinoma . Ann R Coll Surg Engl. 2014, 96:14-16. 10.1308/003588414X13946184901489

4. O'Connor AR, Coakley FV, Meng MV, Eberhardt SC: Imaging of retained surgical sponges in the abdomen and pelvis. AJR Am J Roentgenol. 2003, 180:481-489. 10.2214/ajr.180.2.1800481

5. Lauwers PR, Van Hee RH: Intraperitoneal gossypibomas: the need to count sponges . World J Surg. 2000, 24:521-527. 10.1007/s002689910084

6. Bani-Hani KE, Gharaibeh KA, Yaghan RJ: Retained surgical sponges (gossypiboma). Asian J Surg. 2005, 28:109-115. 10.1016/s1015-9584(09)60273-6 